Original Research Paper

\title{
Passage Effect on Aging of Human Umbilical Cord Derived Mesenchymal Stem Cell
}

\author{
${ }^{1,2}$ Dian Mediana, ${ }^{3,4}$ Isabella Kurnia Liem, ${ }^{3,5}$ Jeanne Adiwinata Pawitan and ${ }^{1,2}$ Noviyanti Goei \\ ${ }^{1}$ Biomedical Master Program, Faculty of Medicine, Universitas Indonesia, Jl. Salemba 6, Jakarta, Indonesia \\ ${ }^{2}$ Department of Anatomy, Faculty of Medicine, Universitas Trisakti, Jl. Kyai Tapa, Jakarta, Indonesia \\ ${ }^{3}$ Stem Cell Medical Technology Integrated Service Unit, Cipto Mangunkusumo Central Hospital, Faculty of Medicine, \\ Universitas Indonesia, CMU 2 Building, 5th Floor, Jl. Diponegoro 71, Jakarta, Indonesia \\ ${ }^{4}$ Department of Anatomy, Faculty of Medicine, Universitas Indonesia, Jl. Salemba 6, Jakarta, Indonesia \\ ${ }^{5}$ Department of Histology, Faculty of Medicine, Universitas Indonesia, Jl. Salemba 6, Jakarta, Indonesia
}

Article history

Received: 14-06-2015

Revised: 17-07-2015

Accepted: 25-07-2015

Corresponding Author: Jeanne Adiwinata Pawitan Departement of Histology, Faculty of Medicine,

Universitas Indonesia, Jl.

Salemba 6, Jakarta, Indonesia

Email: jeanneadiwip@gmail.com

\begin{abstract}
To be used in regenerative medicine, cells should be checked for various conditions, including cell aging. This study aimed to learn senescent profile and its relation to cell viability, proliferation and cell size in various passages, which were done in $\alpha$-MEM-10\% PRP medium, until senescenceassociated $\beta$-galactosidase (SA- $\beta$-Gal) positive cells were found. Stem cells were isolated from umbilical cord tissue by multiple harvest explant method, cultured in $\alpha$-MEM- $10 \%$ PRP until P-17 and stained using SA- $\beta$-Gal staining. Viability, Population Doubling Time (PDT), percentage SA- $\beta-$ Gal $(+)$ and cell size at $30 \%$ confluent and at senescent staining were analyzed. Passages with SA- $\beta-$ Gal $(+)$ and (-) were compared in term of viability, PDT and cell size at $30 \%$ confluent. Further, cell size at senescent staining between SA- $\beta$-Gal $(+)$ and (-) groups were compared. Viability and PDT showed no significant difference between SA- $\beta$-Gal $(+)$ and (-) groups, while cell size at $30 \%$ confluence showed significant increase in SA- $\beta-G a l(+)$ compared to (-) groups. Further, cell size in senescent staining showed significantly smaller cell size in SA- $\beta-$ Gal $(-)$ compared to SA- $\beta-$ Gal $(+)$ cells. Moreover, this study showed that even in SA- $\beta-$ Gal $(+)$ group, viability was greater than $91 \%$, PDT was less than 2.1 days and cell size was less than 2602 $\mu \mathrm{m}^{2}$. In conclusion, umbilical cord derived MSCs that were cultured in $\alpha$-MEM-10\% PRP began to undergo aging at P-10. Morphological criteria of UC-MSC aging were cell size greater than $2602 \mu \mathrm{m}^{2}$ with a change in morphology toward a rounded shape.
\end{abstract}

Keywords: Aging, Stem Cell, Umbilical Cord, Platelet Rich Plasma, Senescence

\section{Introduction}

Use of stem cells for regenerative medicine needs quality control of cell products that includes replicative senescent data. Cells, including adult stem cells can be cultured for limited passages before they undergo aging and this replication-capacity limit is known as "Hayflick limit" (Hayflick, 1965). Aging of cell causes irreversible proliferation-capacity ending that can be triggered by various factors. The factors can be categorized to four factors, i.e.,: DNA damage and shortening of telomere due to excessive linear chromosome replication, which is called replicative senescence; oxidative stress; oncogene activation; and other stressors, such as inadequate in vitro growth condition (Rai and Adam, 2012).

Stem cell long-term culture has a profound effect on proliferation and differentiation potential and cellular morphology. A study found that growth arrest on adipose tissue derived Mesenchymal Stem Cells (MSCs) occured after $138 \pm 20$ days and $53.8 \pm 14.4$ Cumulative Population Doublings (CPD).

Cumulative population doublings were computed from cell seeding and harvest that were cumulated from all passages (Schellenberg et al., 2011).

Passages in culture cause cell senescence. Since early passages, stem cells may show changes toward aging, 
such as decrease in proliferation capacity, morphological changes, shortening of telomeres and functional impairments (Bonab et al., 2005; Wagner et al., 2010). Aging stem cells show characteristic morphologicalappearance as flattened large cells. Moreover, aging cells express senescence-associated beta galactosidase (SA- $\beta$ $\mathrm{Gal}$ ), which can be regarded as biomarker of aging cells (Schellenberg et al., 2013). Increase in SA- $\beta$-Gal activity could be observed since passage 6 (P-6) in bone marrow and adipose tissue derived stem cells, while in Umbilical Cord (UC) derived stem cells since passage 9 to 12 (P-9 to P-12) (Hye et al., 2013). At P5 to P-12, bone marrow derived stem cells showed a decrease in clonogenicity and differentiation potential (Wagner et al., 2010). For gene and cell therapy, a study suggested to use MSCs from P-2 to P-6, the younger the passage, the better (Bonab et al., 2005). Maximal population doublings before senescence depend on type and source of tissue, culture method and culture medium (Hye et al., 2013; Estrada et al., 2013).

Studies on in vitro stem cell culture usually used Fetal Bovine Serum (FBS) supplemented media. As FBS contains xenoproteins that may cause rejection problems, alternatives to FBS were studied. Some studies on Platelet Rich Plasma (PRP) supplemented media showed that PRP can be used as alternative to FBS. Using UC sample, a study showed that PRP can replace FBS as culturemedium supplement, as PRP showed comparable performance to FBS in cell proliferation and differentiation (Budiyanti et al., 2015). Another study reported that MSC isolation from UC using explant culture could be harvested several times and the technique was called multiple harvest explant method (Pawitan et al., 2014a). However, senescent profile of MSCs that were isolated using multiple harvest explant method in $\alpha$ minimal essential medium ( $\alpha$-MEM)-10\% PRP has not been studied, especially in relation to senescenceassociated $\beta$-galactosidase (SA- $\beta-G a l)$ staining and cell size. Therefore, this study was conducted to learn senescent profile and its relation to cell viability, proliferation and cell size in various passages, until SA- $\beta$ Gal positive cells were found in cultures that were cultured in $\alpha$-MEM-10\% PRP medium.

\section{Materials and Methods}

This study was done in Stem Cell Medical Technology Integrated Service Unit, Cipto Mangunkusumo Central Hospital/Faculty of Medicine Universitas Indonesia, from April to November 2014. Ethical clearance was issued by the Ethical Committee of the Faculty of Medicine, Universitas Indonesia (No.665/UN2.F1/ETIK/2014). Stem cells for this study were isolated from an umbilical cord that was donated by a woman who underwent an elective Caesarean section and has signed the informed consent form.

\section{Procedure}

Stem cell isolation was done using modification of multiple harvest explant method (Pawitan et al., 2014a). In brief, UC was washed and immersed in $0.5 \%$ povidone iodine containing Phosphate Buffered Saline pH 7.4 (PBS) for $5 \mathrm{~min}$, followed by washing in PBS. Umbilical arteries and vein were discarded and UC tissue was minced in complete medium to small pieces (2-5 $\mathrm{mm})$. Complete medium was penicillin/ streptomycin ([Biosera LM-A4118/100] final concentration $100 \mathrm{U} / \mathrm{mL}$ ), amphotericin B ([Gibco 15290-018] final concentration $2500 \mathrm{ng} / \mathrm{mL}), 1 \%$ GlutaMAX and $10 \%$ PRP containing $\alpha-$ MEM [Gibco 12000-014]. One piece of minced UC tissue was placed in a well of a 24 well-plate (area 1.9 $\mathrm{cm} 2$ [Biolite]) and a drop of complete medium was added to the tissue (explant). All process was done under sterile condition. Further, the plate was incubated at $37^{\circ} \mathrm{C}, 5 \% \mathrm{CO}_{2}$ and was observed everyday during the Primary culture $(\mathrm{P} 0)$ period. Observation was done to prevent the explant from drying by adding a necessary amount of medium. When the explant attached to the well, $0.2 \mathrm{~mL}$ fresh complete medium was added and medium change was done every 2-3 days. Observation was also done to detect cell growth. After cell growth was $70-80 \%$, the cells were harvested using TrypLE Select (Gibco 12563-011).

Harvested cells were re-cultured to P-1 in six 12-well plate (area $3.8 \mathrm{~cm} 2$ [Biolite]), with a seeding density of 5000 viable cells $/ \mathrm{cm} 2$. After $70-80 \%$ confluence, cells from two wells were harvested and cells from four wells were fixed and stained using senescent staining kit (Sigma CS0030-1KT). Senescent cells were SA- $\beta-G a l$ positive, which showed blue-green color that was apparent after 12-16 h of incubation. Further, harvested cells were re-cultured in six 12-well plate again and again to yield P-2 until P-17.

\section{Cell Size Measurement}

At $30 \%$ confluence, cells from all wells were photographed (40×magnification) using inverted microscope at five random fields to measure cell size (area). Cell area was measured using AxioVision Rel.4.8 program on the photograph (in $\mu \mathrm{m}^{2}$ ). For each passage, fifty randomly chosen fibroblastic (spindle shaped) cells were measured.

Cells in SA- $\beta$-Gal-stained wells were photographed $(100 \times$ magnification) using inverted microscope at five random fields to count SA- $\beta-$ Gal $(+)$ cells and all cells. Further, cell area of six randomly chosen SA- $\beta-$ Gal $(+)$ and (-) cells from each well was measured using AxioVision Rel.4.8 program on the photograph (in $\mu \mathrm{m}^{2}$ ). 


\section{Cell Viability Analysis}

Harvested cells were counted using improved Neubauer haemocytometer and checked for their viability by tryphan blue dye exclusion method. Ten $\mu 1$ of cell suspension was mixed with the same volume of $0.4 \%$ trypan blue solution, inserted into the haemocytometer and after 1-2 min at room temperature, viable and non-viable cell-count was done. Further, cell viability (percentage of viable cells per total cells) was calculated for each passage.

\section{Data Collection and Analysis}

Data collected from P-1 to P-17 were: Time to confluence, viability, Population Doubling Time (PDT), cell size (at $30 \%$ confluence and at senescent staining) and percentage of senescent (SA- $\beta-G a l+)$ cells. Senescent data were grouped into SA- $\beta-G a l(+)$ and (-) passages. Passage-1 was not included as was regarded as heterogeneous. All data were tabulated and means and standard deviations were calculated, but when the data did not show normal distribution or non homogenous, median was analyzed. Further, Cumulative Population Doubling (CPD) at P-17 was calculated.

Population doubling time was calculated using the equation: $\mathrm{PDT}=(\mathrm{t}-\mathrm{t} 0) \log 2 /(\log \mathrm{Nt}-\log \mathrm{Nt} 0)$, where $\mathrm{Nt}=$ total cell count at harvest, $\mathrm{Nt} 0=$ viable cell count at seeding, $\mathrm{t}=$ time at harvest and $\mathrm{t} 0=$ time at seeding. Cumulative population doubling was calculated by summing up all population doublings of all passages until P-17.

Data analysis was done using Statistical Product and Service Solution (SPSS) version 16.0 program. Comparison of cell viability, PDT and cell size at $30 \%$ confluent between SA- $\beta-$ Gal $(+)$ and $(-)$ groups were done using independent $t$ test, when the data were appropriate for parametric analysis. Further, cell size at senescent staining between SA- $\beta$-Gal (+) and (-) groups from the same wells were compared using paired $t$ test, when the data were appropriate for parametric analysis.
For all comparisons, when the data were inappropriate for parametric tests, non parametric tests were done.

\section{Results}

Mean value of viability, PDT and cell size at $30 \%$ confluence can be seen in Table 1. Cumulative population doubling until P-17 was 61.23 times, cumulative culture time was 76 days and mean time to $70-80 \%$ confluence was 4.6 days. Median (minimummaximum value) of viability and PDT of P-2 to P-17 was $95.92(90.73-99.73) \%$ and $1.61(0.99-2.02)$ days respectively. Positive SA- $\beta$-Gal cells were first found at P-10 with a median (minimum-maximum value) of 0 (0$0.54) \%$. Therefore, the data were grouped according to SA- $\beta-G a l(-)$ and (+), i.e. P-2 to P-9 and P-10 to P-17. Median (minimum-maximum value) of SA- $\beta-$ Gal $(+)$ cells from P-10 to P-17 was $0.54(0-3.41) \%$. Viability, PDT and cell size at $30 \%$ confluence of UC MSCs in P-2 to P-9 and P-10 to P-17 groups can be seen in Table 2 .

Table 1. Viability, PDT and cell size at $30 \%$ confluent of cells in P-2 to P-17

\begin{tabular}{llll}
\hline Passage & Viability & PDT & Cell size \\
\hline P-2 & 91.59 & 1.87 & 2188.64 \\
P-3 & 96.51 & 1.11 & 2803.78 \\
P-4 & 96.82 & 1.12 & 2911.45 \\
P-5 & 93.45 & 1.16 & 2575.72 \\
P-6 & 94.49 & 1.73 & 2229.75 \\
P-7 & 99.73 & 1.98 & 2100.49 \\
P-8 & 98.80 & 1.61 & 2677.63 \\
P-9 & 98.48 & 1.69 & 3079.98 \\
P-10 & 93.64 & 1.46 & 2797.60 \\
P-12 & 95.34 & 1.62 & 4051.48 \\
P-13 & 97.75 & 1.22 & 3664.33 \\
P-14 & 96.76 & 1.62 & 3588.15 \\
P-15 & 92.39 & 1.34 & 4384.95 \\
P-16 & 95.34 & 0.99 & 3624.64 \\
P-17 & 90.73 & 2.02 & 4527.19 \\
\hline P- Passag
\end{tabular}

$\mathrm{P}-=$ Passage

Table 2. Viability, PDT and cell size at 30\% confluence of umbilical cord MSCs in P-2 to P-9 and P-10 to P-17 group

\begin{tabular}{lllllll}
\hline & Group & $\mathrm{n}$ & Mean & SD & $\mathrm{p}$ & Mean difference (95\% CI) \\
\hline Viability & P-2 to P-9 & 87 & 96.23 & 2.84 & 0.71 & $1.27(-1.62-+4.17)$ \\
& P-10 to P-17 & 87 & 94.96 & 2.54 & & \\
PDT & P-2 to P-9 & 87 & 1.53 & 0.35 & 0.49 & $0.04(-0.32-+0.40)$ \\
\multirow{2}{*}{ Cell size } & P-10 to P-17 & 87 & 1.50 & 0.32 & & \\
& P-2 to P-9 & 400 & 2571 & 363 & 0.00 & $1193(-1694--692)$ \\
& P-10 to P-17 & 400 & 3764 & 552 & & \\
\hline
\end{tabular}

$\mathrm{PDT}=$ Population Doubling Time, $\mathrm{MSCs}=$ Mesenchymal Stem Cells, $\mathrm{P}=$ passage, $\mathrm{SD}=$ Standard Deviation, $\mathrm{p}=\mathrm{p}$ value, $\mathrm{CI}=$ Confidence Interval

Table 3. Cell size of umbilical cord derived MSCs in SA- $\beta$-Gal (-) and (+) group

\begin{tabular}{|c|c|c|c|c|}
\hline Cell size & Mean (SD) & Difference (SD) & $95 \% \mathrm{CI}$ & $\mathrm{p}$ \\
\hline SA- $\beta-$ Gal (-) $(n=36)$ & $1860(742)$ & $2045(1816)$ & $-2611--1479$ & 0.00 \\
\hline SA- $\beta-G a l(+)(n=36)$ & 3905 (1934) & & & \\
\hline
\end{tabular}

MSCs $=$ Mesenchymal Stem Cells, SA- $\beta-$ Gal $=$ Senescence Associated- $\beta$-galactosidase, $\mathrm{n}=$ experiment number, SD $=$ Standard Deviation, $\mathrm{CI}=$ Confidence Interval, $\mathrm{p}=\mathrm{p}$ value 


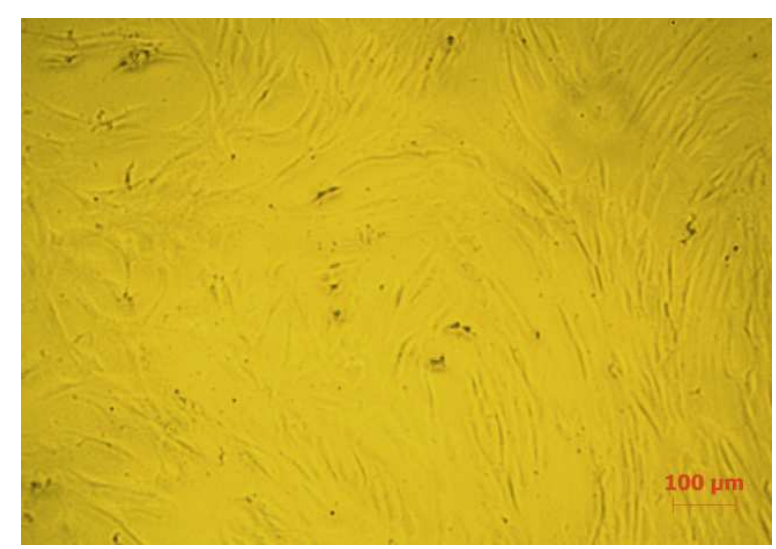

$\mathrm{P}-2-100 \times($ negative $)$

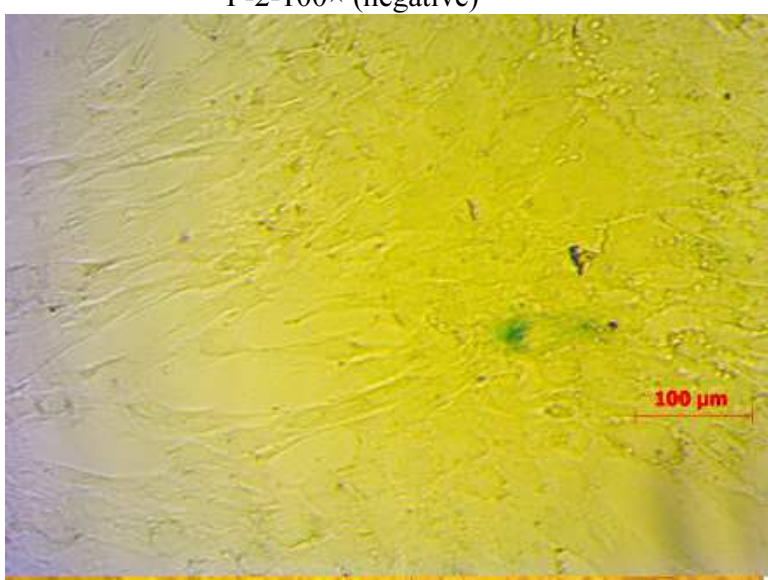

P10-200× (positive)

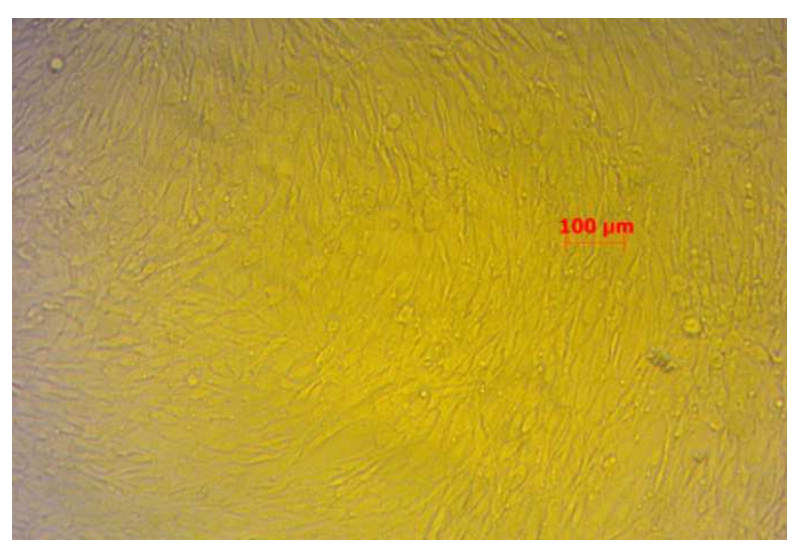

P-9-100× (negative)

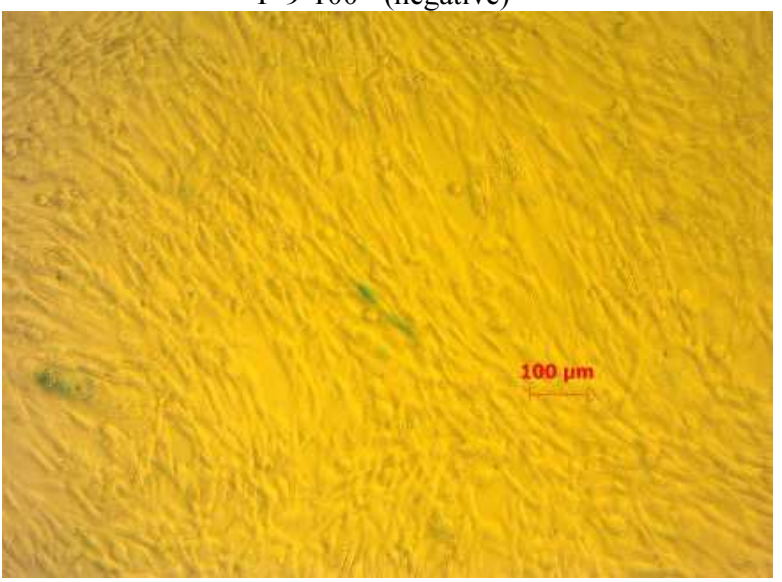

P17-100× (positive)

Fig. 1. SA- $\beta-$ Gal staining of mesenchymal stem cells from P-2, P-9, P-10 and P-17

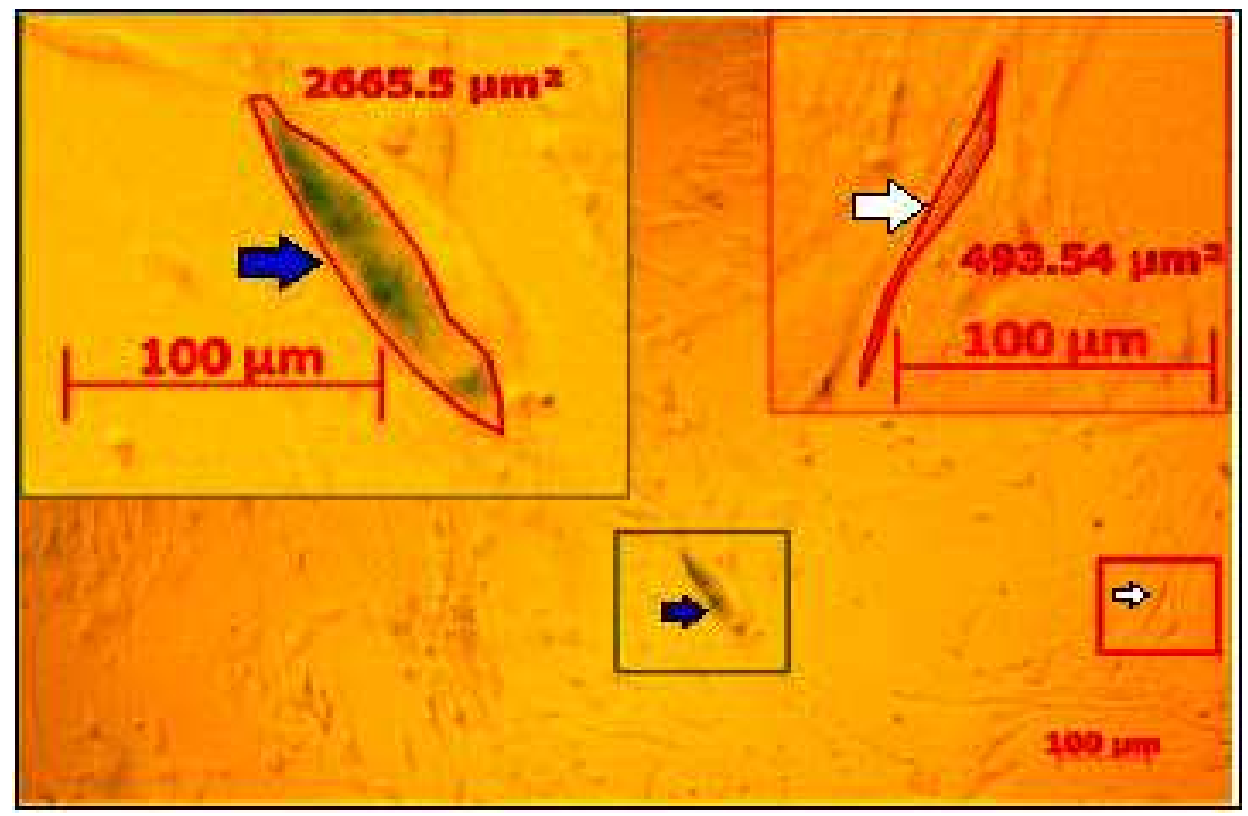

Fig. 2. Morphological appearance of UC-MSCs in SA- $\beta$-Gal staining $(100 \times)$ UC-MSCs $=$ umbilical cord derived mesenchymal stem cells, SA- $\beta-\mathrm{Gal}=$ senescence associated $\beta$-galactosidase, blue arrow $=$ SA- $\beta-$ Gal $(+)$ cell, white arrow $=$ SA- $\beta-$ Gal $(-)$ cell, inset $=$ enlargement 
Independent $t$ test on viability and PDT showed no significant difference between P-2 to P-9 and P-10 to P-17 group, while cell size at $30 \%$ confluence showed a significant increase in $\mathrm{P}-10$ to $\mathrm{P}-17$ compared to $\mathrm{P}-2$ to P-9 group.

Mean value and standard deviation of cell size of UC - MSCs in SA- $\beta$-Gal staining, difference between SA- $\beta$ Gal $(+)$ and $(-)$ group, $95 \%$ confidence interval and $p$ value of the difference can be seen in Table 3 .

Paired $\mathrm{t}$ test on cell size of UC MSCs showed significantly smaller cell size in SA- $\beta-$ Gal (-) compared to SA- $\beta-$ Gal $(+)$ group (Table 3 ). However, data of SA$\beta$-Gal staining did not include data of P-11, as P-11 culture had undergone retraction and was detached when it was stained.

Figure 1 showed negative SA- $\beta$-Gal staining (P-2 and P-9) and positive SA- $\beta$-Gal staining (P-10 and P-17). Figure 2 showed morphological appearance of UCMSCs in SA- $\beta$-Gal staining. An SA- $\beta-$ Gal $(+)$ cell (blue arrow) was larger and wider in diameter compared to an SA- $\beta-$ Gal (-) cell that was more fibroblastic in shape.

\section{Discussion}

Passage caused UC - MSCs to undergo aging. Aging stem cells express $\beta$-Galactosidase due to increase in lisosomal activity. $\beta$-Galactosidase activity can be detected by adding 5-bromo-4-chloro-3-indolyl $\beta$-Dgalactopyranoside (X-Gal), a chromogenic substrate that upon cleavage gives rise to blue green precipitates (Dimri et al., 1995). In this study, SA- $\beta-G a l(+)$ cells began to be detected at P-10 and median (minimummaximum) value of positive cells was $0.54(0-3.41) \%$ that indicated the beginning of aging process. A study found that SA- $\beta-G a l(+)$ cells in UC blood MSCs began to increase at P-9 to P-12 (Hye et al., 2013), while another study found $5-10 \%$ SA- $\beta$-Gal $(+)$ cells in early passages of UC - MSCs, which increase between $38.2 \pm$ $9.4 \%$ in $\mathrm{P}-15$ and $71.5 \pm 8.8 \%$ in P-21 (Scheers et al., 2013). Scheers et al. (2013) used DMEM-10\% FBS with a seeding density of $1.10^{4}$ cells $/ \mathrm{cm}^{2}$, while Hye el al. (2013) used $\alpha$-MEM - 10\% FBS with a seeding density of $5.10^{5}$ cells $/ \mathrm{cm}^{2}$ and we used $\alpha$-MEM- $10 \%$ PRP with a seeding density of 5000 cells $/ \mathrm{cm}^{2}$. Further, a study showed that serum supplemented medium caused a fast increase in percentage of senescent cells from $22.79 \pm 0.77 \%$ in P-3 to $30.22 \pm 11.07 \%$ in $\mathrm{P}-5$ (Swamynathan et al., 2014).

Therefore, an increase in percentage of senescent UC-MSCs is influenced by culture medium and CPD, while seeding density influence PD. At higher seeding density, less PD is needed to attain confluence and causes lower CPD. Therefore, the higher the seeding density, the faster passage can be done and the number of passage for a certain CPD will be relatively higher.
Seeding density in the study of Hye et al. (2013) was 100 times of those in this study, while senescent in Hye et al. (2013) study began at P-9 to P-12, which seemed equivalent with the result of this study, but theoretically CPD in Hye et al. (2013) study was lower. Therefore, higher passage can't be used as a reference; instead, CPD plays a more important role, as CPD is actually the reference for achievement of Hayflick's limit, i.e., when the cells undergo aging and lose their ability to proliferate (Hayflick, 1965; Schellenberg et al., 2011; Bonab et al., 2005; Wagner et al., 2010). Therefore, aging at lower CPD indicates that the cells undergo faster aging.

Moreover, the sample in Hye et al. (2013) study was UC blood that contained very few MSCs (Bieback et al., 2004). Fewer initial number of MSCs theoretically causes more $\mathrm{PD}$ in $\mathrm{P}-0$ to attain confluence compared to UC - MSCs, though PD in P-1 and higher passages are not influenced. However, high PD at P0 certainly increases overall CPD.

In this study, viability at P-2 to P-17 was still very high with a median (minimum-maximum) of 95.92 (90.73-99.73) \%. Another study on human Wharton's jelly-derived stem cell viability found that viability at P10 was still $>82 \%$ and the highest viability was achieved at P-5 or P-6, which also showed an increase in proliferation rate (Garzón et al., 2012). Decreased cell viability is associated with cell necrosis. $\mathrm{Na}^{+}$and $\mathrm{K}^{+}$ions are cell viability markers and $\mathrm{K}^{+} / \mathrm{Na}^{+}$ratio is used as indicator of cell damage. An increase in $\mathrm{Na}^{+}$and a decrease in $\mathrm{K}^{+}$and $\mathrm{Cl}^{-}$occur in cell death due to apoptosis, while high concentration of $\mathrm{Cl}^{-}$is associated with cell necrosis. The study showed a decrease in intracellular $\mathrm{K}^{+}$level at $\mathrm{P}-1$ to $\mathrm{P}-3$ followed by an increase until P-7 and a significant decrease beginning at $\mathrm{P}-8$ and beyond. $\mathrm{Cl}^{-}$level was significantly increased at P-7, P-8 and following passages. These facts indicated that at $\mathrm{P}-1$ to $\mathrm{P}-3$, cell death was due to apoptosis, while beginning at P7-8, cell death was due to necrosis, which caused the highest viability at P5 and P6 (Garzón et al., 2012). However, there was no data concerning physiological level of these ions in UC - MSCs.

In this study, viability is checked by trypan blue dye exclusion method. We did not checked the viability using any other method, such as the 3-(4, 5dimethylthiazol-2-yl)-2-5-diphenoltetrazolium bromide (MTT) assay and this fact is the limitation of our study. Viability assay in our study might be influenced by trypan blue concentration and incubation time at cell counting procedure. A study on human retinal pigment epithelial cells compared trypan blue $0.06 \mathrm{mg} / \mathrm{mL}, 0.6$ $\mathrm{mg} / \mathrm{mL}$ and $4 \mathrm{mg} / \mathrm{mL}$ and found increased expression of p53 at trypan blue concentration of $4 \mathrm{mg} / \mathrm{mL}$, while increase in p21 expression was found at all concentration. It was supposed that higher trypan blue 
concentration caused toxicity that was indicated by a decrease in viability and alteration in gene expression that was related to apoptosis and growth arrest. Moreover, longer incubation caused cell death and a decrease in viable cell number (Kwok et al., 2004). This study used trypan blue concentration of $0.4 \%$ with trypan blue: Cell suspension ratio $=1: 1$ and incubation time 1-2 min, which was supposed to be non toxic and would not interfere with the result of this study.

Proliferation capacity of MSCs decreases with passage. In this study, median (minimum-maximum value) of PDT for P-2 to P-17 was 1.61 (0.99-2.02) days, which indicated good proliferation capacity. Another study found a decrease in MSC-PDT from $85 \pm 7.2 \mathrm{~h}$ at P0 to $11 \pm 1.2 \mathrm{~h}$ at P-7. They calculated PDT at P0 as time needed from initial culture in DMEM-10\% FBS until $100 \%$ confluent and cell number was analyzed at several points during log phase (Karahuseyinoglu et al., 2007). Another study on DMEM - 10\% FBS cultured UCMSCs at first 15-passages found that mean value \pm SD of PDT at P-1 to P-15 was $3.1 \pm 0.4$ days; a decrease in proliferation rate and final growth arrest occurred at CPD mean value \pm SD of $33.7 \pm 2.1$ doublings; whole culture period was $160.9 \pm 6.9$ days, number of passages was $21 \pm 1.0$ passages (Scheers et al., 2013). Various factors may influence proliferation rate of MSCs, including culture medium, type of enzyme at harvesting (e.g., TryplE Select), time interval between seeding and harvest and passage (Osipova et al., 2011). A study on culture of bone marrow MSCs indicated that proliferation potential in serum free medium was lower than in FCS supplemented medium (Osipova et al., 2011). However, another study showed that PRP was more mitogenic compared to FBS (Murphi et al., 2012) and this fact might explain the different proliferation rate in our study compared to other studies that used FBS supplementation (Scheers et al., 2013; Karahuseyinoglu et al., 2007). Moreover, serum and PRP batches may play a role in the difference. In our study, we did not compare different batches of PRP and this fact was a limitation to our study.

Morphology of MSCs before aging is fibroblastic, but when the cells underwent aging as were shown by senescent staining, the aging cells became larger and broader and cell size (area) was significantly larger compared to non senescent cells. Scheers et al. (2013) studied early passages of UC-MSCs and observed small fibroblastic cells with a diameter of $14.1 \pm 0.7 \mu \mathrm{m}$ that progressively flattened and enlarged to $22.3 \pm 0.8 \mu \mathrm{m}$ upon aging. Aging cells showed low proliferation rate, prolonged mitosis time and enlarged cell area (Scheers et al., 2013). Scheers et al. (2013) study was corroborated by our study, which showed that SA- $\beta$-Gal positive group (P-10 to P-17) had a larger cell area compared to SA- $\beta-G a l$ negative group (P-2 to P-9). However, P-10 to P-17 group still showed good viability and PDT, which might be due to the low median (minimum-maximum) of senescent (SA- $\beta$-Gal positive) cell percentage in this group that was $0.54(0-3.41) \%$.

In analysis we only included passages beginning at P-2. Passage-1 was not included as flow cytometric data of CD90, CD73 and CD34 showed that P-1 was heterogeneous. In P2, the cells were regarded as UC- MSCs from their fibroblastic morphology, adherent to plastic, flow cytometry analysis and differentiation capacity.

In $\mathrm{P}-11$, SA- $\beta$-Gal positive cells could not be assessed as the culture was too confluent, which caused detachment of monolayer from the well bottom and this fact was a limitation of our results. Senescent cells in P11 seemed to be higher compared to those in P-10. This fact might be due to relatively more confluent monolayer contained more cells, including the senescent cells. Another possibility was that over-confluent cultures tended to differentiate (Pawitan et al., 2014b) and after differentiation, the cells would lose their self renewal capacity and undergo aging.

This study showed that for UC-MSCs the criteria for aging cells besides SA- $\beta$-Gal positive were: Viability greater than $91 \%$ (minimum value), PDT less than 2.1 days (maximum value), fibroblastic morphology and cell size (area) less than $2602 \mu \mathrm{m}^{2}$ (maximum value).

\section{Conclusion}

Umbilical cord derived MSCs that were cultured in $\alpha$-MEM-10\% PRP began to undergo aging at P-10. Morphological criteria of aging UC-MSCs were cell size greater than $2602 \mu \mathrm{m}^{2}$ with a change in morphology toward a wider or rounded shape.

\section{Acknowledgement}

We are indebted to all staff of Stem Cell Medical Technology Integrated Service Unit, Cipto Mangunkusumo Central Hospital-Faculty of Medicine Universitas Indonesia, PT. Kimia Farma and Cellsafe who has assisted in maintaining the lab facility and sample collection. Finally, we would like to appreciate the donor who donated the umbilical cord tissue.

\section{Funding Information}

This study was funded by a grant from the Department of National Education of the Republic of Indonesia (PUSNAS 2015, contract number: 0435/UN2.R12/HKP.05.00/2015). 


\section{Authors Contributions}

Dian Mediana: Cell culture, data collection and analysis, writing whole manuscript in Indonesian and final approval of translated manuscript.

Isabella Kurnia Liem: Development of research idea, analysis of whole data, reading draft and final approval of manuscript.

Jeanne Adiwinata Pawitan: Development of research idea, supervising research work, analysis of whole data, translating of whole manuscript and final approval of manuscript.

Noviyanti Goei: Cell culture, data collection and analysis and final approval of manuscript.

\section{Ethics}

This study was approved by the Ethical Committee of the Faculty of Medicine, Universitas Indonesia (No.665/UN2.F1/ETIK/2014).

\section{Conflict of Interest}

All authors declare that there is no conflict of interest.

\section{References}

Bieback, K., S. Kern, H. Klüter and H. Eichler, 2004. Critical parameters for the isolation of mesenchymal stem cells from umbilical cord blood. Stem Cells, 22: 625-634. DOI: 10.1634/stemcells.22-4-625

Bonab, M., K. Alimoghaddam, F. Talebian, S.H. Ghaffari and A. Ghavamzadeh et al., 2005. Assessment of in vitro aging of mesenchymal stem cell. IJHOBMT, 2: 34-39.

Budiyanti, E., I.K. Liem, J.A. Pawitan, D. Wulandari and T. Jamaan et al., 2015. Umbilical cord derived mesenchymal stem cell proliferation in various platelet rich plasma and xeno-material containing medium. Int. J. Res. Pharmaceutical Sci., 6: 7-13.

Dimri, G.P., X.H. Lee, G. Basile, M. Acosta and G. Scott et al., 1995. A biomarker that identifies senescent human cells in culture and in aging skin in vivo. Cell Biol., 92: 9363-9367.

Estrada, J.C., Y. Torres, A. Benguria, A. Dopazo and E. Roche et al., 2013. Human mesenchymal stem cellreplicative senescence and oxidative stress are closely linked to aneuploidy. Cell Death Dis., 4: e691-e691. DOI: 10.1038/cddis.2013.211

Garzón, I., B. Pérez-Köhler, J. Garrido-Gómez, V. Carriel and R. Nieto-Aguilar et al., 2012. Evaluation of the cell viability of human Wharton's jelly stem cells for use in cell therapy. Tissue Eng. Part C Methods, 18: 408-419.

DOI: $10.1089 /$ ten.tec. 2011.0508
Hayflick, L., 1965. The limited in vitro lifetime of human diploid cell strains. Eksperimental Cell Res., 37: 614-636. DOI: 10.1016/0014-4827(65)90211-9

Hye, J.J., K.B. Yun, M. Kim, S.J. Kwon and B.J. Hong et al., 2013. Comparative analysis of Human Mesenchymal Stem Cells from bone marrow, adipose tissue umbilical cord blood as sources of cell therapy. Int. J. Mol. Sci., 14:17986-8001. DOI: $10.3390 / \mathrm{ijms} 140917986$

Karahuseyinoglu, S., O. Cinar, E. Kilic, G.G. Akay and D.O. Demiralp et al., 2007. Biology of stem cells in human umbilical cord stroma: In situ and in vitro surveys. Stem Cells, 25: 319-331. DOI: $10.1634 /$ stemcells.2006-0286

Kwok, A.K.H., C.K. Yeung, T.Y.Y. Lai, K.P. Chan and C.P. Pang, 2004. Effects of trypan blue on cell viability and gene expression in human retinal pigment epithelial cells. Br. J. Ophthalmol., 88: 1590-1594. DOI: 10.1136/bjo.2004.044537

Murphi, M.B., D. Blashki, R.M. Buchanan, I.K. Yazdi and M. Ferrari et al., 2012. Adult and umbilical cord blood-derived platelet-rich plasma for mesenchymal stem cell proliferation, chemotaxis cryopreservation. Biomaterials, 33: 5308-5316. DOI: 10.1016/j.biomaterials.2012.04.007

Osipova, E.Y., T.V. Shamanskaya, O.A. Kurakina, V.A. Nikitina and B.B. Purbueva et al., 2011. Biological characteristics of mesenchymal stem cells during ex vivo expansion. Br. J. Med. Medical Res., 1: 85-95. DOI: $10.9734 / B J M M R / 2011 / 282$

Pawitan, J.A., I.K. Liem, E. Budiyanti, I. Fasha and L. Feroniasanti et al., 2014a. Umbilical cord derived stem cell culture: multiple-harvest explant method. Int. J. Pharm. Tech. Res., 6: 1202-1208.

Pawitan, J.A., D. Suryani, D. Wulandari, L. Damayanti and I.K. Liem et al., 2014b. Prolonged culture in FBS and FBS-substitue containing media: Spontaneous chondrogenic differentiation of adipose tissue derived mesenchymal stem cells. Int. J. Pharm.Tech. Res., 6: 224-235.

Rai, T.S. and P.D. Adam, 2012. Lessons from senescence: Chromatin maintenance in nonproliferating cells. Biochim. Biophys. Acta, 1819: 322-331. DOI: 10.1016/j.bbagrm.2011.07.014

Scheers, I., C. Lombard, M. Paganelli, D. Campard and M. Najimi et al., 2013. Human umbilical cord matrix stem cells maintain multilineage differentiation abilities and do not transform during long-term culture. PLoS ONE, 8: e71374- e71374. DOI: $10.1371 /$ journal.pone.0071374

Schellenberg, A., H. Hemeda and W. Wagner, 2013. Tracking of replicative senescence in mesenchymal stem cells by Colony-Forming Unit frequency. Stem Cells Aging, 976: 143-154.

DOI: 10.1007/978-1-62703-317-6_11 
Schellenberg, A., Q. Lin, H. Schüler, C.M. Koch and S. Joussen et al., 2011. Replicative senescence of mesenchymal stem cells causes DNA-methylation changes which correlate with repressive histone marks. Aging, 3: 873-888. PMID: 22025769

Swamynathan, P., P. Venugopal, S. Kannan, C. Thej and U. Kolkundar et al., 2014. Are serum-free and xenofree culture conditions ideal for large scale clinical grade expansion of Wharton's jelly derived mesenchymal stem cells? A comparative study. Stem Cells Res. Therapy, 5: 1-17.

DOI: $10.1186 /$ scrt 477 .
Wagner, W., S. Bork, G. Lepperdinger, S. Joussen and N. Ma et al., 2010. How to track cellular aging of mesenchymal stromal cells? Aging, 2: 224-230. PMID: 20453259 